\title{
STRATEGIC RISK MANAGEMENT IN DESIGN COMPANIES (BASED ON LLC GIPROSINTEZ)
}

\author{
Irina V. Borisova \\ LLC Giprosintez, Volgograd, Russian Federation
}

\begin{abstract}
The article reviews the risks that affect design activities with reference to and critical analysis of existing publications on risk management efficiency. As a result of systematization of risks, the most common problems in the field of design are characterized and a program for managing strategic risks is compiled. The strategic risk management program describes the existing categories of strategic risks that design companies tend to face, the design company's strategic risk analysis, the strategic risk protection policy, strategic risk management scenarios and the organizational breakdown structure for evaluating and managing strategic risks, and the strategic risk management program monitoring procedures. The risk systematization identifies some risk categories, such as operational strategic risks (production risks including personnel-, technology-, planning-, industry- and financerelated, and commercial risks) and strategy-inherent risks. The author suggests a method for risk assessment by expert evaluation. The strategic risk management scenarios presented herein outline the measures that, being properly implemented, decrease the probability of risk occurrence and thus enable to make the risks more controllable and promptly respond to external and internal challenges. The strategic risk management program suggested by the author helps configure the potential strategic approaches to ensure financial stability of a design company.

Key words: strategic risk, design activity, strategic risk management, program, strategic risk analysis.

Citation. Borisova I.V. Strategic Risk Management in Design Companies (Based on LLC Giprosintez). Journal of Volgograd State University. Economics, 2020, vol. 22, no. 1, pp. 135-145. (in Russian). DOI: https://doi.org/ 10.15688/ek.jvolsu.2020.1.12
\end{abstract}

\section{УПРАВЛЕНИЕ СТРАТЕГИЧЕСКИМИ РИСКАМИ В ПРОЕКТНЫХ ОРГАНИЗАЦИЯХ (НА ПРИМЕРЕ ООО «ГИПРОСИНТЕЗ»)}

\section{Ирина Владимировна Борисова}

ООО «Гипросинтез», г. Волгоград, Российская Федерация

\begin{abstract}
Аннотация. В статье в рамках критического анализа опубликованных материалов по проблеме эффективности управления рисками исследованы риски, оказывающие влияние на проектную деятельность. В результате их систематизации охарактеризованы наиболее распространенные проблемы в сфере проектирования и составлена программа управления стратегическими рисками. Эта программа описывает существующие группы стратегических рисков проектных организаций, анализ стратегического риска проектной организации, политику защиты от стратегических рисков, сценарии управления стратегическими рисками проекحิ тных организаций, организационную структуру по распределению обязанностей по оценке и управлению стратегическими рисками на проектном предприятии и контроль за исполнением программы управления стратегическим риском. Выделены несколько групп рисков: оперативные стратегические риски (производственные риски, в том числе кадровые, технологические, отраслевые, финансовые, коммерческие и риски планирования) и собственные риски стратегии. Предложен вариант оценки рисков методом экспертных оценок. Представленные сценарии управления стратегическими рисками позволяют усилить контроль за () рисками и способность оперативно реагировать на воздействия внешней и внутренней среды, так как опи-
\end{abstract}


сывают действия, которые необходимо выполнять для сокращения вероятности наступления рискового события. Предлагаемая программа управления стратегическими рисками позволит сформировать возможные стратегические направления обеспечения финансовой устойчивости проектной организации.

Ключевые слова: стратегический риск, проектная деятельность, управление стратегическим риском, программа, анализ стратегического риска.

Цитирование. Борисова И. В. Управление стратегическими рисками в проектных организациях (на примере ООО «Гипросинтез») // Вестник Волгоградского государственного университета. Экономика. 2020. - T. 22, № 1. - C. 135-145. - DOI: https://doi.org/10.15688/ek.jvolsu.2020.1.12

\section{Введение}

В настоящее время наблюдается снижение спроса на проектную продукцию, что привело к сокращению количества проектных организаций. По данным Волгоградстата, на территории Волгоградской области число организаций, занимающихся строительной, в том числе проектной деятельностью, каждый год сокращается: в 2017 г. их количество составило 4903 организации, 2018 г. - 4 459, 2019 г. - 4105 [Территориальный орган ... , 2019]. Сфера строительства, являясь наиболее зависимой от банковского сектора, оказалась неспособной оперативно реагировать на воздействие внешних и внутренних факторов. Спрос на проектную продукцию формировали не только частные инвесторы, но и государство. Несмотря на сокращение заказов, проектные организации не изменили свою стратегию, выбранную в период высокого спроса. Отсутствие системы управления стратегическими рисками усложнило управление проектной деятельностью.

Стратегическое планирование является основным элементом по управлению рисковыми факторами (формированию эффективных механизмов адаптации к изменениям во внешней среде). Однако ошибки при разработке и реализации стратегии могут не только снизить эффективность выбранной стратегии организации, но и оказаться губительными для бизнеса [Холмс, 2007, c. 304]. Целью исследования является разработка программы управления стратегическими рисками, адаптированная для проектной организации. Для ее достижения необходимо решить ряд задач: определить основные разделы рассматриваемой программы и описать их, выявить и систематизировать стратегические риски, существующие в проектной деятельности.

\section{Методика}

В исследовании использовались научные (специальные) методы - экспертная оценка, анализ и синтез, факторный анализ. Кроме того, применялся метод конкретизации, выраженный в детальном изучении вопроса управления стратегическими рисками в рамках проектной организации.

\section{Результаты и обсуждения}

Риск представляет собой вероятность наступления события, которое может оказать влияние на достижение целей организации. Риск существует всегда, поэтому одной из задач организации является снижение вероятности наступления рискового события или минимизация последствий уже наступившего события. Эффективность управления рисками определяется правильной идентификацией рисков по разработанной классификации. Рисковое событие - это случай или ситуация, возникающая в результате действия внутренних и внешних факторов (обусловливающих существование риска как такового), которое оказывает влияние на деятельность организации и достижение поставленных целей [Филина, 2008, с. 232].

В процессе проектной деятельности руководство сталкивается с совокупностью различных видов рисков, которые следует классифицировать с учетом специфики деятельности проектных организаций.

В настоящее время в связи с переходом на ускоренные темпы инновационного развития проектных организаций, интеграции и растущей потребности в научно-технических разработках, высокой конкуренции и глобализации производственных связей резко расширился круг проблем, связанных с вопросами управления стратегическими рисками проек- 
тных организаций. Для их успешного решения необходимо создание программы управления стратегическими рисками на проектном предприятии в современных условиях.

Стратегическое управление представляет собой деятельность руководства предприятия, которая состоит в выборе сферы и образа действия по достижению долгосрочных целей в условиях постоянно меняющейся среды, и является одной из важнейших функций стратегического планирования [Олейник, 2002, c. 182].

Программа управления стратегическими рисками на проектном предприятии должна состоять из разделов, учитывающих особенности данной деятельности. Предлагаем следующую структуру программы:

1. Цель программы.

2. Область применения.

3. Нормативные ссылки.

4. Термины, определения, сокращения и условные обозначения.

4.1. Термины и определения.

4.2. Сокращения.

4.3. Условные обозначения.

5. Описание программы.

6. Выделение системы стратегических рисков проектной организации.

7. Анализ стратегического риска проектной организации. рисков.

8. Политика защиты от стратегических

9. Сценарии управления стратегическими рисками проектных организаций.

10. Организационная структура по распределению обязанностей по оценке и управлению стратегическими рисками на проектном предприятии.

11. Контроль за исполнением программы управления стратегическим риском.

12. Документирование, архивирование, рассылка документа.

Составленный по данной структуре документ обсуждается рабочей группой во главе с руководителем проектной организации. Далее он согласовывается с экспертами (руководителями подразделений проектной организации), а затем передается на утверждение руководителю. После этого данный документ становится неотъемлемой частью системы менеджмента качества проектной организации и все управленческие решения должны опираться на него.

Программа управления стратегическими рисками пересматривается ежегодно. При необходимости в нее вносятся корректировки, соответствующие современным требованиям и изменениям внешней и внутренней среды проектной организации.

Рассмотрим группы стратегических рисков на примере $\mathrm{OOO}$ «Гипросинтез».

1. Оперативные стратегические риски.

1.1. Производственные риски.

- Технологические риски:

1.1.1. Снижение качества произведенной проектной продукции.

1.1.2. Принятие исполнителем решений, расходящихся с мнением заказчика.

1.1.3. Риск невозможности исполнения требований заказчика.

1.1.4. Риск технического отставания от современных технологий проектирования.

- Риски планирования:

1.1.5. Ошибки в разграничении сроков и ресурсов для проведения запланированных мероприятий.

1.1.6. Риск срыва сроков выполнения работ.

1.1.7. Риск изменения стоимости проектных работ.

- Кадровые риски:

1.1.8. Риск недостатка квалифицированных кадров.

1.1.9. Риск недостатка исполнителей.

1.1.10. Риск снижения производительности труда.

1.2. Отраслевые риски.

1.2.1. Увеличение количества конкурентов.

1.2.2. Снижение объемов государственного заказа.

1.3. Финансовые риски.

1.3.1. Процентный риск из-за неблагоприятных изменений процентных ставок.

1.3.2. Валютный риск, связанный с интернационализацией рынка банковских операций.

1.3.3. Инфляционный риск, связанный с ростом инфляции.

1.3.4. Дефицит оборотных средств.

1.3.5. Увеличение дебиторской задолженности.

1.3.6. Сокращение банковского финансирования. 
1.4. Коммерческие риски.

1.4.1. Риск неполучения новых работ (проигрыш на конкурсных площадках и в тендерах на выполнение проектных работ) - сокращение количества заказов на выполнение проектных работ.

1.4.2. Риск будущего сотрудничества с недобросовестным заказчиком (фактическое отсутствие денежных средств у заказчика для оплаты заказа).

1.4.3. Транспортные риски, связанные с периодом доставки проектной продукции.

1.4.4. Риск контрагента, связанный с финансовой устойчивостью основных партнеров проекта (подрядчик, гаранты, заказчик, страховые компании и т. д.).

1.4.5. Риск неисполнения контракта субподрядными организациями.

1.4.6. Риск досрочного расторжения контракта.

2. Собственные риски стратегии.

2.1. Формирование неадекватного ассортимента проектных услуг.

2.2. Отсутствие четкой стратегии.

2.3. Экологический риск, связанный с любым потенциальным негативным воздействием строительного проекта на окружающую среду.

2.4. Возражение общественности в случае проведения публичных слушаний с целью получения экологического заключения.

2.5. Непрохождение государственной экспертизы (неполучение согласований) проектной документации с первого раза.

2.6. Возникновение судебных разбирательств.

2.7. Концентрация на внешних источниках финансирования.

2.8. Отсутствие преимуществ перед конкурентами.

Итак, выделен комплекс стратегических рисков проектной организации, который станет базой для проведения количественной оценки. Существует множество методов оценки стратегических рисков, однако наиболее экономичными являются метод экспертных оценок и статистический метод.

Статистические методы довольно часто используются на практике, так как позволяют получить наиболее точную картину об уровне риска. При оценке вероятности изучается статистика потерь и прибылей, имевших место ранее, устанавливается величина и частота того или иного экономического результата, составляется наиболее вероятностный прогноз на будущее. Вместе с тем возникают ситуации, когда по различным причинам использование статистического метода не представляется возможным [Шерышева, 2007, c. 254-258]. К категории таких рисков можно отнести прежде всего риски стратегии.

Метод экспертных оценок предполагает применение опыта человека. При правильной организации экспертизы результаты, полученные по итогам проведения экспертных оценок, являются достоверными, несмотря на отсутствие математических доказательств.

На проектном предприятии анализ стратегического риска проектной организации выполняется методом экспертных оценок, опирающимся на алгоритм анализа риска, предложенный В.В. Шереметом [Шеремет, 1998, c. 411].

1. Каждый риск оценивается по шкале от 0 до 1. Предельная норма риска устанавливается проектной организацией на основании оценки рисков за пять лет.

2. Уровень компетентности экспертов определяется руководством проектной организации. В круг экспертов входят 5 человек. Оценка их компетентности имеет 10-балльную шкалу и является конфиденциальной.

3. Количество неблагоприятных последствий за год по риску выставляется экспертами с точки зрения наступления рискового события. Максимально возможное число неблагоприятных последствий за год по риску равно количеству проектов, выполненных и выполняемых в отчетном году. Форма, подлежащая заполнению каждым экспертом, представлена в таблице 1.

4. Оценки, проставленные экспертами по каждому виду риска, сводятся в таблице 2 . В ней также определяется интегральный уровень по каждой группе стратегических рисков.

5. Данные интегрального уровня риска и предельный уровень риска заносятся в таблицу 3. В ней также делается заключение по каждой группе стратегических рисков. Если предельный уровень риска ниже полученных результатов, то предлагаются меры, направленные на снижение вероятности наступления выявленных рисковых событий. 
И.В. Борисова. Управление стратегическими рисками на проектных организациях

Таблица 1

Экспертный анализ стратегического риска

\begin{tabular}{|c|c|c|c|c|}
\hline $\begin{array}{c}\text { № } \\
\text { П/п }\end{array}$ & $\begin{array}{c}\text { Наименование } \\
\text { риска }\end{array}$ & $\begin{array}{c}\text { Количество неблаго- } \\
\text { приятных последст- } \\
\text { вий за год по риску }\end{array}$ & $\begin{array}{c}\text { Максимально возможное } \\
\text { число неблагоприя тных } \\
\text { последствий за год по риску }\end{array}$ & Величина риска \\
\hline 1 & 2 & 3 & 4 & гр. $5=$ гр. $3 /$ гр. 4 \\
\hline
\end{tabular}

Примечание. Составлено автором.

Таблица 2

Экспертный анализ стратегического риска

«Наименование риска (по группам рисков)»

\begin{tabular}{|c|c|c|c|c|}
\hline $\begin{array}{c}\text { № } \\
\text { п/п }\end{array}$ & $\begin{array}{c}\text { Ф.И.О. } \\
\text { эксперта }\end{array}$ & $\begin{array}{c}\text { Уровень } \\
\text { компетентности } \\
\text { эксперта }\end{array}$ & $\begin{array}{c}\text { Величина риска } \\
\text { (гр. 5 табл. 1) }\end{array}$ & $\begin{array}{c}\text { Интегральный уровень } \\
\text { риска }\end{array}$ \\
\hline 1 & 2 & 3 & 4 & гр. 5= гр. 3 х гр. 4 \\
\hline & & & & $\begin{array}{c}\text { (SUM по стб. 5) / } \\
\text { (кол-во экспертов) }\end{array}$ \\
\hline
\end{tabular}

Примечание. Составлено автором.

Таблица 3

\section{Выявление уровня риска}

\begin{tabular}{|c|c|c|c|c|}
\hline $\begin{array}{c}\text { № } \\
\text { п/п }\end{array}$ & $\begin{array}{c}\text { Наименование } \\
\text { риска }\end{array}$ & $\begin{array}{c}\text { Интегральный } \\
\text { уровень риска } \\
\text { (итог табл. 2) }\end{array}$ & $\begin{array}{c}\text { Предельный } \\
\text { уровень риска }\end{array}$ & $\begin{array}{c}\text { Заключение (допустимый } \\
\text { уровень риска/ } \\
\text { недопустимый уровень } \\
\text { риска) }\end{array}$ \\
\hline 1 & 2 & 3 & 4 & 5 \\
\hline
\end{tabular}

Примечание. Составлено автором.

После проведения экспертной оценки разрабатывается политика защиты от стратегических рисков, которая и включает разработку мер по предупреждению и снижению уровня стратегического риска. Политика защиты от стратегических рисков на проектном предприятии построена на внутренних механизмах нейтрализации - экономических и физических.

Физические механизмы нейтрализаичии: защита данных от несанкционированного доступа, сигнализация, приобретение сейфов, система контроля качества продукции, охрана офиса.

Экономические методы управления возможными рисками: отказ от ненадежных субподрядных организаций и заказчиков, страхование, поиск гарантов, мониторинг, прогнозирование, активный целенаправленный маркетинг, резервирование, расширение сферы услуг, создание резервных фондов.

Сценарии управления стратегическими рисками проектных организаций описывают, как избежать рисковых событий или снизить их влияние по каждому риску.
Сценарии управления технологическими рисками включают:

1. Увеличение количества контролирующих лиц проектной продукции, согласование с заказчиком максимального количества решений по проектированию до начала выполнения работ.

2. Назначение ответственных лиц за отслеживание современных программ по проектированию.

Сценарии управления рисками планирования включают:

1. Согласование разработанных графиков выполнения работ с заказчиком.

2. Согласование сметы на выполнение работ с заказчиком.

Сценарии управления кадровыми рисками содержат следующие пункты:

1. Дополнительная подготовка персонала. Она включает выполнение таких мероприятий, как:

- проведение дополнительной подготовки и аттестацию персонала проектной бригады по промышленной безопасности в облас- 


\section{УПРАВЛЕНИЕ ЭКОНОМИЧЕСКИМ РАЗВИТИЕМ}

тях, требуемых для выполнения проекта (при необходимости);

- проведение дополнительной подготовки и тестирование персонала проектной бригады по технической подготовке по вопросам, составленным на основании замечаний экспертов, нормоконтроля главных специалистов организации;

- проведение дополнительной подготовки и тестирование персонала проектной бригады по применяемому расчетному и прикладному программному обеспечению, необходимому для выполнения проекта.

Перечень вопросов дополнительной подготовки, составленный персонально по составу проектной бригады, график обучения и тестирования разрабатываются начальником технического отдела, согласовываются с заместителями технического директора, утверждаются техническим директором.

Ответственность за своевременность и качество выполнения мероприятий по дополнительной подготовке персонала проектной бригады несут: заместитель технического директора по организации проектирования и подготовке кадров, начальник технического отдела.

2. Предоставление информации начальниками отделов о необходимых кадрах.

3. Определение соотношения составляющих производительности труда: трудовая дисциплина - 5 \%, применение аналогов $30 \%$, внедрение расчетно-моделирующих программ - $15 \%$, применение технологий 3D-проектирования - $25 \%$, внедрение программ автоматизации проектирования $-25 \%$; контроль основных социально-экономических показателей деятельности.

4. Диагностика основных социально-экономических показателей деятельности.

На рисунке приведен пример анализа основных показателей деятельности ООО «Гипросинтез».

Сценарии управления финансовыми рисками включают:

1. Минимизацию объема привлекаемых заемных средств.

2. Наращивание объема собственных средств.

3. Распределение финансовых ресурсов по участникам проектирования.

В ведомости распределения финансовых средств должны быть предусмотрены:

- резерв на непредвиденные расходы;

- распределение финансовых средств по этапам работ в соответствии с календарным планом проектирования.

Она должна быть подписана главным инженером проекта, начальником финансово-экономического отдела, заместителем технического директора по организации проектирования и подготовке кадров, согласована техни-

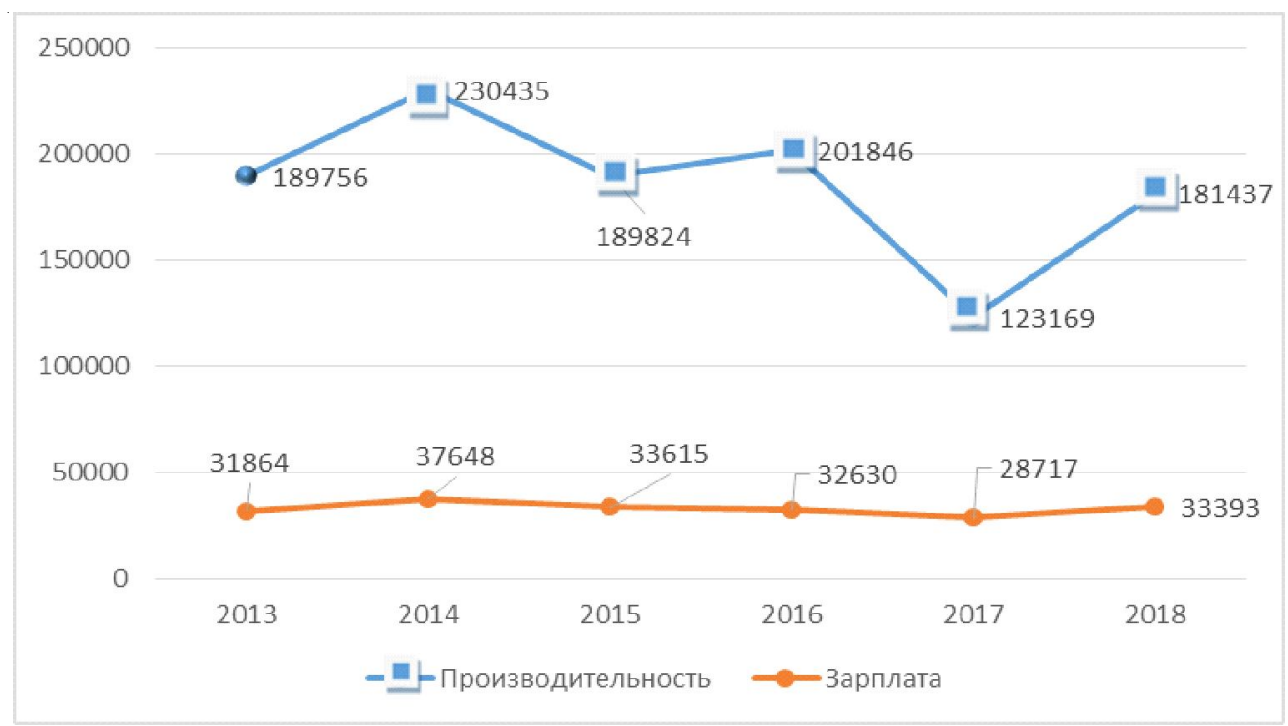

Рисунок. Основные социально-экономические показатели деятельности ООО «Гипросинтез» (на основании учетных данных ООО «Гипросинтез)

Примечание. Составлено автором. 
ческим директором, утверждена генеральным директором организации. Ответственность за своевременность и качество подготовки распределения финансовых средств несет главный инженер проекта.

Сценарии управления отраслевыми рисками включают следующие пункты: работ.

1. Повышение качества выполняемых

В ходе проектирования применяется трехуровневый оперативный контроль.

1-й уровень - автоматизированный контроль сроков выполнения проектирования по графикам работ. Контроль осуществляют:

а) финансовый отдел и утвержденные руководством проектной организации графики на проектирование. Задания на разработку смежных разделов (частей) проектной продукции являются обязательным элементом процесса проектирования;

б) начальники производственных отделов, которые организуют и проводят оценку технического уровня заданий, выдаваемых смежными отделами с привлечением руководителя сектора и ответственного исполнителя, принимающего задание. Анализ качества заданий выполняет начальник производственного отдела. Результаты анализа представляются главному инженеру, который обобщает полученную информацию и разрабатывает сводный отчет «Анализ результативности системы менеджмента качества»;

в) главный инженер при работе с ответственными исполнителями по рассмотрению состояния разработки проекта. Рассмотрение осуществляется в части исполнения графиков, текущих проблемных вопросов, затрудняющих проектирование. Периодичность этого процесса определяется главным инженером с учетом объема и сроков выполняемых работ. Рассмотрение состояния разработки проекта рекомендуется осуществлять по следующим вопросам:

- обеспечение выполнения проекта (условия выполнения работ: обеспеченность персоналом, оборудованием, нормативно-технической документацией, программными средствами);

- выполнение решений протоколов предыдущих совещаний;

- выполнение сроков обмена заданиями согласно графику;
- наличие изменения заданий;

- мероприятия по обеспечению корректировки хода выполнения работ (при необходимости);

- прочие текущие вопросы.

Принятые на совещании решения должны оформляться протоколом. Оригинал протокола хранится у главного инженера.

2-й уровень - еженедельный контроль выполнения задач проектирования по докладам главного инженера и начальников производственных отделов на совещаниях.

Главный инженер еженедельно на совещаниях докладывает руководству проектной организации о состоянии проектных работ по закрепленным объектам.

В докладе отражается следующая информация:

- наименование работы, объект проектирования;

- состояние выполнения проектных работ, планируемая дата выхода на контрольную точку проектирования, проблемные вопросы.

Начальники производственных отделов еженедельно на совещаниях докладывают руководству проектной организации о состоянии проектных работ по закрепленным объектам в подчиненном подразделении.

В докладе отражается следующая информация:

- расстановка проектировщиков по объектам проектирования, планируемые и понесенные трудозатраты, проблемные вопросы по выполнению задач проектирования. Для еженедельных и ежемесячных докладов начальники производственных отделов формируют отчеты по планируемым и фактическим трудозатратам исполнителей.

3-й уровень - выборочный контроль качества выполнения отдельных мероприятий.

Реализуется руководителем подразделения, обеспечивающего процесс проектирования, по указанию технического директора или его заместителя по организации процесса проектирования и подготовки кадров.

2. Получение оценок и отзывов о выполненных работах от заказчиков.

После оформления акта сдачи-приемки выполненных работ последнего этапа главный инженер проекта обязан направить заказчику формализованные запросы «Показатели удов- 


\section{УПРАВЛЕНИЕ ЭКОНОМИЧЕСКИМ РАЗВИТИЕМ}

летворенности Заказчика» (табл. 4) и «Отзыв о работе Организации по выполнению проекта» с целью получения информации об удовлетворении заказчика предоставляемыми организацией услугами. Полученные от заказчика отзывы главный инженер проекта обязан:

- направить для использования в рекламных целях;

- включить в журнал-отчет технического сопровождения проекта;

- использовать при проведении анализа результативности системы менеджмента качества в проектной организации.

3. Участие в тендерах на выполнение государственных заказов.

Сценарии управления коммерческими рисками включают:

1. Повышение количества заявок на участие в тендерах и конкурсах на проектирование.

2. Проверка истории работы будущего заказчика.
3. Предоставление проектной продукции за 10 дней до срока поставки указанного в договоре.

4. Утверждение процедуры подбора и контроля субподрядных организаций.

Поиск субподрядных организаций для выполнения проекта осуществляют на основании решения стартового совещания, определяющего перечень работ, выполняемых с привлечением субподрядчиков.

При выборе субподрядчиков должны быть учтены следующие условия:

- опыт выполнения аналогичных работ, в том числе в кооперации с организацией;

- оценка работы субподрядной организации при выполнении работ в кооперации за последние три года;

- наличие положительных отзывов о выполнении работ от заказчика проекта и других заказчиков в случае первоначального привлечения субподрядчика к работе;

Оценочные показатели выполненной работы (пример заполнения)

\begin{tabular}{|c|c|}
\hline \multicolumn{2}{|l|}{ Заказчик: } \\
\hline \multicolumn{2}{|l|}{ Наименование работы: } \\
\hline \multicolumn{2}{|l|}{ Стадия проектирования: } \\
\hline Наименование показателя & Возможное значение показателя \\
\hline \multicolumn{2}{|r|}{ 1. Качество работы } \\
\hline $\begin{array}{l}\text { 1.1. Соответствие документации требо- } \\
\text { ваниям технического задания на вы- } \\
\text { полнение работы }\end{array}$ & $\frac{\text { полное /частичное/ не соответствует }}{\text { (ненужное зачеркнуть })}$ \\
\hline $\begin{array}{l}\text { 1.2. Уровень принятых проектных ре- } \\
\text { шений }\end{array}$ & $\frac{\text { современный /стандартный/ ниже ожиданий }}{\text { (ненужное зачеркнуть) }}$ \\
\hline \multicolumn{2}{|c|}{ 2. Коммуникации } \\
\hline $\begin{array}{l}\text { 2.1. Взаимодействие на этапе заключе- } \\
\text { ния договора и сбора исходных данных }\end{array}$ & $\begin{array}{c}\frac{\text { конструктивное / без замечаний / необходим контроль }}{\text { (ненужное зачеркнуть) }} \\
\end{array}$ \\
\hline $\begin{array}{l}\text { 2.2. Взаимодействие в процессе проек- } \\
\text { тирования (согласование технических решений, ком- } \\
\text { поновки, подбор оборудования.) }\end{array}$ & $\frac{\text { конструктивное / без замечаний / необходим контроль }}{\text { (ненужное зачеркнуть) }}$ \\
\hline $\begin{array}{l}\text { 2.2. Взаимодействие в процессе приема- } \\
\text { сдачи документации (оперативное рассмотрение } \\
\text { и устранение замечаний и рекомендаций) }\end{array}$ & $\frac{\text { конструктивное / без замечаний / необходим контроль }}{\text { (ненужное зачеркнуть) }}$ \\
\hline \multicolumn{2}{|l|}{ 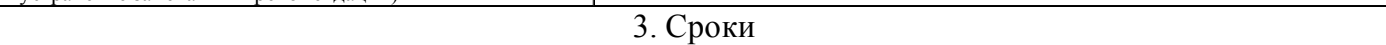 } \\
\hline $\begin{array}{l}\text { 3.1. Соблюдение договорных сроков } \\
\text { выполнения работы }\end{array}$ & $\frac{\text { безусловное / задержки промежуточных этапов / срыв }}{\text { (ненужное зачеркнуть) }}$ \\
\hline \multicolumn{2}{|l|}{ Замечания и рекомендации: } \\
\hline \multicolumn{2}{|l|}{ Выводы и обобщения: } \\
\hline \multicolumn{2}{|l|}{$\begin{array}{l}\text { Должность } \\
\text { Дата заполнения }\end{array}$} \\
\hline
\end{tabular}

Примечание. Составлено автором. 
- наличие собственной производственной базы, обученного персонала, имеющего допуск к осуществлению заявленной деятельности, аттестованного по промышленной безопасности;

- стоимость технико-коммерческого предложения субподрядчика.

Перечень субподрядных организаций, которые планируется привлечь к работе (не менее трех организаций), определяют ответственные лица в сроки, указанные в протоколе стартового совещания.

Решение о возможности привлечения субподрядчика к работе определяет комиссия в составе главного инженера проекта, технического директора и его заместителей. Оно должно быть утверждено генеральным директором организации и согласовано заказчиком проекта.

Ответственность за своевременность и качество выполнения мероприятий по подбору и согласованию с заказчиком субподрядчиков несет главный инженер проекта.

Договор с субподрядной организацией должен заключаться только при согласовании с заказчиком возможности ее привлечения к работам над проектом. Работу по оформлению договора организует главный инженер проекта совместно с финансовым отделом.

Документы, необходимые для заключения договора (дополнительных соглашений к договору), разрабатывает сметно-договорная группа финансового отдела на основании таких материалов, как:

- задание на выполнение проектных работ, утвержденное генеральным директором организации. Оно должно соответствовать заданию, утвержденному заказчиком;

- протокол согласования договорной цены, утвержденный генеральным директором;

- календарный план выполнения работ по договору (наименование этапов, стоимость работ по этапам, исполнитель этапов, сроки выполнения этапов - месяц, дата), утвержденный генеральным директором.

Документы, необходимые для заключения договора, предоставляет главный инженер проекта, который несет персональную ответственность за их своевременность и достоверность.
Задание на проектирование субподрядной организации разрабатывает ответственный исполнитель, по профильной деятельности которого заключается договор. Оно должно быть согласовано заместителями технического директора - главными специалистами (по профилю) и техническим директором, подписано главным инженером.

Прием продукции, разработанной субподрядной организацией, осуществляется в два этапа.

1-й этап. В течение 5 рабочих дней после поступления в организацию продукция должна быть рассмотрена профильными ответственными исполнителями.

По результатам рассмотрения составляется Перечень замечаний и рекомендаций, который согласовывается с заместителями технического директора - главными специалистами. Ответственность за организацию рассмотрения несут главный инженер и производственные отделы, за качество рассмотрения - ответственные специалисты.

2 -й этап. В течение 3 рабочих дней после формирования сводного Перечня замечаний и рекомендаций продукция и перечень замечаний должны быть рассмотрены на техническом совете (по решению технического директора). Сводный Перечень замечаний и рекомендаций и сроки их устранения утверждаются решением технического совета. Ответственность за разработку сводного перечня и подготовку материалов к проведению технического совета несет главный инженер.

После устранения субподрядной организацией выявленных замечаний, выполнения рекомендаций главный инженер и финансовый отдел организуют работу по оформлению акта сдачи-приемки выполненных работ. Акт сдачи-приемки выполненных работ субподрядной организации оформляется после получения оформленного генерального акта от заказчика.

Сценарии управления собственными рисками стратегии включают:

1. Проверку действующих лицензий на выполнение работ, своевременное продление лицензий.

2. Разработку и утверждение стратегии проектной организации. 
3. Своевременное прохождение экологической экспертизы проектной документации (состав и требования к оформлению проектной продукции, направляемой на государственную экологическую экспертизу, определены требованиями Федерального закона от 23.11.1995 № 174-Ф3 «Об экологической экспертизе»).

4. Подготовку проектной документации к государственной экспертизе согласно требованиям Главгосэкпертизы РФ, своевременное устранение замечаний экспертов (состав и требования к оформлению проектной документации, направляемой на государственную экспертизу, определены требованиями Постановления Правительства РФ от 05.03.2007 № 145 «О порядке организации и проведения государственной экспертизы проектной документации и результатов инженерных изысканий»).

5. Своевременное прохождение экспертизы промышленной безопасности (состав и требования к оформлению проектной продукции, направляемой на экспертизу промышленной безопасности, определены требованиями Федерального закона от 21.07.1997 № 116-Ф3 «О промышленной безопасности опасных производственных объектов»).

6. Расширение сферы предоставляемых услуг (приобретение новых лицензий, обучение специалистов новым направлениям деятельности, привлечение специалистов, разработка и приобретение компьютерных программ).

7. Оперативный анализ замечаний к проектной продукции.

На основе согласованного заказчиком ответа (заключения) проектной организации или полученного заключения экспертного органа по рассмотрению проектной продукции, представленной на экспертизу на замечания к проектной продукции, организуется работа по формированию:

- сводного перечня замечаний заказчика по составным частям проекта с указанием категории замечания;

- списка проектировщиков, допустивших ошибки в ходе выполнения проекта, с указанием нормативных документов, нарушение требований которых допущено;

- аналитической справки с указанием наименования подразделений организации, числа допущенных нарушений по категориям, количества трудозатрат на подготовку ответов (заключений) и внесение изменений в проектной продукции.

Разработанные аналитические материалы должны быть согласованы главным инженером проекта, заместителем технического директора по организации проектирования и подготовки кадров, утверждены техническим директором. Срок подготовки аналитических материалов не должен превышать 10 рабочих дней.

Организационная структура по распределению обязанностей по оценке и управлению стратегическими рисками на проектном предприятии представляет собой схему, в которой прописаны ответственные лица за контроль каждого риска. Контроль за исполнением программы управления стратегическим риском осуществляет отдел качества ежегодно собирающий отчеты о выполнении этой программы. Документирование, архивирование, рассылка документа производится согласно порядку, прописанному в программе управления стратегическим риском.

\section{Выводы}

Внедрение программы управления стратегическими рисками в систему менеджмента качества проектной организации позволит повысить финансовую устойчивость проектных организаций с позиции управления стратегическими рисками. Наиболее эффективным методом оценки стратегических рисков для проектной организации является метод экспертных оценок. Разработка базовых сценариев управления стратегическими рисками позволит оперативно реагировать на возникновение рисков и предотвратить их возникновение.

\section{СПИСОК ЛИТЕРАТУРЫ}

Киров, А. В. Управление финансовой устойчивостью фирмы в контексте ресурсно-факторного подхода : автореф. дис. ... д-ра экон. наук / Киров Александр Владимирович. Волгоград, 2012. - 46 c.

Олейник, А. Б. Экономическая устойчивость предприятия в современных условиях : дис. ... канд. 
экон. наук / Олейник Андрей Борисович. Волгоград, 2002. - 198 с.

Территориальный орган Федеральной службы государственной статистики по Волгоградской области. Распределение организаций по видам экономической деятельности. - Электрон. текстовые дан. - Режим доступа: http:// volgastat.gks.ru/wps/wcm/connect/rosstat_ts/ volgastat/resources/1096c90048bc547e-8 fb $99 \mathrm{fb} 3 \mathrm{ce} 167 \mathrm{dd} 4 / \% \mathrm{D} 0 \% 9 \mathrm{E} \% \mathrm{D} 0 \% 9 \mathrm{~A} \% \mathrm{D} 0 \%$ $92 \% \mathrm{D} 0 \% \mathrm{AD} \% \mathrm{D} 0 \% 942+\% \mathrm{D} 0 \% \mathrm{BD} \% \mathrm{D} 0 \% \mathrm{~B} 0+$ 01012019.pdf. - Загл. с экрана.

Филина, Ф. Н. Риск-Менеджмент : монография / Ф. Н. Филина. - М. : ГроссМедия : РОСБУХ, 2008. $-232 \mathrm{c}$.

Холмс, Э. Риск-менеджмент : монография / Э. Холмс. - М. : Эксмо, 2007. - 304 с.

Шеремет, В. В. Управление инвестициями. В 2 т. Т. 1 : справ. пособие для специалистов и предпринимателей / В. В. Шеремет. - М. : Высш. шк., 1998. $-411 \mathrm{c}$

Шерышева, Л. Н. Стратегические цели организации - нужно и можно измерять // Управленческий учет и финансы. - 2007. - № 3 (11). C. 254-258.

\section{REFERENCES}

Kirov A.V. Upravlenie finansovoy ustoychivostyu firmy $v$ kontekste resursno-faktornogo podkhoda: avtoref. dis. ... d-ra ekon. nauk [Resources FactorBased Approach to the Management of a Firm's Financial Stability. Dr. econ. sci. abs. diss.]. Volgograd, 2012.46 p.
Oleynik A.B. Ekonomicheskaya ustoychivost predpriyatiya $v$ sovremennykh usloviyakh: dis. ... kand. ekon. nauk [Economic Stability of a Business in the Present-Day Conditions. Dr. econ. sci. abs. diss]. Volgograd, 2002. 198 p.

Territorialnyy organ Federalnoy sluzhby gosudarstvennoy statistiki po Volgogradskoy oblasti. Raspredelenie organizatsiy po vidam ekonomicheskoy deyatelnosti [Territorial Office of the Federal State Statistics Service for Volgograd Region. Classification of Companies According to Their Nature of Business]. URL: http://volgastat.gks.ru/wps/wcm/connect/ rosstat_ts/volgastat/resources/1096c90048bc $547 \mathrm{e} 8 \mathrm{fb} 99 \mathrm{fb} 3 \mathrm{ce} 167 \mathrm{dd} 4 / \% \mathrm{D} 0 \% 9 \mathrm{E} \% \mathrm{D} 0 \% 9 \mathrm{~A} \% \mathrm{D}$ $0 \% 92 \%$ D0\%AD $\%$ D0\% $\% 42+\%$ D0\%BD $\%$ D0 $\% \mathrm{~B} 0+01012019$.pdf.

Filina F.N. Risk-Menedzhment: monografiya [Risk Management. Monograph] Moscow, GrossMedia Publ., ROSBUKh Publ., 2008. 232 p.

Kholms E. Risk-menedzhment: monografiya [Risk Management. Monograph]. Moscow, Eksmo Publ., 2007. 304 p.

Sheremet V.V. Upravlenie investitsiyami. V 2 t. T. 1 : sprav. posobie dlya spetsialistov $i$ predprinimateley [Investment Management. In 2 Vols. Vol. 1. Reference Book for Specialists and Entrepreneurs]. Moscow, Vysshaya shkola Publ., 1998. 411 p.

Sherysheva L.N. Strategicheskie tseli organizatsii nuzhno i mozhno izmeryat [Strategic Goals of a Company Can Be and Must Be Measured]. Upravlencheskiy uchet i finansy [Management Accounting and Finance Journal], 2007, no. 3 (11), pp. 254-258.

\section{Information About the Author}

Irina V. Borisova, Category I Engineer, Project Chief Engineers Bureau, LLC "Giprosintez", Raboche-Krestyanskaya St., 30a, 400074 Volgograd, Russian Federation, irvlads@mail.ru, https://orcid.org/0000-0003-4617-3735

\section{Информация об авторе}

Ирина Владимировна Борисова, инженер первой категории бюро главных инженеров проекта, ООО «Гипросинтез», ул. Рабоче-Крестьянская, 30а, 400074 г. Волгоград, Российская Федерация, irvlads@mail.ru, https://orcid.org/0000-0003-4617-3735 